Sahin, O., Bertone, E., Beal, C., Stewart, R.A., 2018. Evaluating a novel

tiered scarcity adjusted water budget and pricing structure using a

holistic systems modelling approach. Journal of Environmental Management

215, 79-90.https://doi.org/10.1016/j.jenvman.2018.03.037

\title{
Evaluating a novel tiered scarcity adjusted water budget and pricing structure using a holistic systems modelling approach
}

\author{
$\underline{\text { Oz Sahin }}{ }^{\mathrm{a}, \mathrm{b}}$, Edoardo Bertone ${ }^{\mathrm{b}, \mathrm{c}}$, Cara Beal $^{\mathrm{b}, \mathrm{c}}$, and Rodney A. Stewart ${ }^{\mathrm{b} . \mathrm{c}}$ \\ ${ }^{a}$ Griffith Climate Change Response Program, Griffith University, QLD, Australia \\ (o.sahin@griffith.edu.au) \\ ${ }^{b}$ Griffith School of Engineering and Built Environment, Griffith University, QLD, Australia \\ ${ }^{c}$ Cities Research Institute, Griffith University, QLD, Australia
}

\begin{abstract}
:
Population growth, coupled with declining water availability and changes in climatic conditions underline the need for sustainable and responsive water management instruments. Supply augmentation and demand management are the two main strategies used by water utilities. Water demand management has long been acknowledged as a least-cost strategy to maintain water security. This can be achieved in a variety of ways, including: i) educating consumers to limit their water use; ii) imposing restrictions/penalties; iii) using smart and/or efficient technologies; and iv) pricing mechanisms. Changing water consumption behaviours through pricing or restrictions is challenging as it introduces more social and political issues into the already complex water resources management process. This paper employs a participatory systems modelling approach for: (1) evaluating various forms of a proposed tiered scarcity adjusted water budget and pricing structure, and (2) comparing scenario outcomes against the traditional restriction policy regime. System dynamics modelling was applied since it can explicitly account for the feedbacks, interdependencies, and non-linear relations that inherently characterise the water tariff (price)-demand-revenue system. A combination of empirical water use data, billing data and customer feedback on future projected water bills facilitated the assessment of the suitability and likelihood of the adoption of scarcity-driven tariff options for a medium-sized city within Queensland, Australia. Results showed that the tiered scarcity adjusted water
\end{abstract}


budget and pricing structure presented was preferable to restrictions since it could maintain water security more equitably with the lowest overall long-run marginal cost.

Keywords: Water demand management; water conservation; scarcity pricing; water restrictions; system dynamics.

\section{Introduction}

\subsection{Demand management strategies}

The urban water utilities in Australia and around the world are struggling to meet the increasing demand for water as they are confronted by a number of challenges including severe droughts, increasing population, highly variable rainfall, and ageing infrastructure. Supply augmentation and demand management are two main strategies used by water utilities. In order to guarantee long-term water security, the water utilities need to diversify water supply investments while improving the efficiency of water use through implementing a range of demand management strategies.

To provide water security under a range of uncertainties, utilities undertake long term planning with forecast cycles of 20-30 years (Cole et al., 2012). Complex decisions are made on how to balance the need to augment the water supply capacity, while ensuring the financial sustainability of expensive infrastructure and water services through cost recovery as well as implementing effective demand management strategies (DMS). DMS are considered to be the lowest-cost water security measure and have the potential to significantly reduce consumption of a region in terms of system leakage (Girard and Stewart, 2007), household leakage (Britton et al., 2013), water efficient appliance retrofits (Beal et al., 2012), real-time water consumption monitoring (Nguyen et al., 2013), water consumption behavioural change communication (Fielding et al., 2013) and technologies (Stewart et al., 2013). A key question is: to what extent could the water utilities satisfy the water demand of a rapidly growing population? This issue was extensively debated during the Millennium drought between 1997 and 2009 in Australia (Pittock and Connell, 2010). Substantial water supply investment decisions are usually prompted during a water security crisis; however, as observed during the Millennium drought, often they do not deliver the desired outcomes when needed (Sahin et al., 2015). This is usually due to limited knowledge about future conditions, inadequate capabilities to handle uncertainties, and short political timeframes.

In Australia, supply augmentations, solutions, such as constructing new dams, are typically used as one of the main strategies to meet a long-term demand growth. However, in recent years, water utilities have begun considering a more reliable supply of water alternatives due to limited availability of suitable dam sites and potential impacts of changing climate, e.g.: climate-independent water supply 
systems. Further, many water utilities have also engaged in water efficiency initiatives with rebate schemes, while exploring the concept of Time of Use Tariffs (e.g. Wide Bay Water Corporation in Queensland, Australia) to target high water users in order to reduce their demand on the system by utilising smart meter technologies across their city (Cole et al., 2012). Although these new options are more reliable, they also require significantly higher capital and operating costs (Hughes et al., 2009). Thus, if water utilities continue building new infrastructure without managing the demand, the capital investments, as well as the operational and maintenance costs of these assets will increase the financial burden upon the utilities and jeopardise the services over time. Therefore, water utilities have been increasingly exploring the benefit of implementing demand management measures to reduce peak water demand. DMS is another key policy instrument for water utilities for planning and managing water resources (Beal et al., 2016). DMS includes: i) educating consumers to limit their consumption and incentivising improvements in water use efficiency; ii) imposing water use restrictions or / penalties for high use; iii) use of smart technologies; and iv) pricing mechanisms. Key objectives of DMS are to reduce the consumption to the level of available water supply capacity and to defer the new expensive capital infrastructure investments.

\subsection{Rethinking traditional water pricing and restriction policy}

High demand triggers a need for additional supply and subsequent construction of water infrastructure. Interactions between demand, supply and infrastructure/assets are complex, interdependent and dynamic over time. Water pricing and water use restrictions are two key demand management mechanisms for water use efficiency and conservation resulting in differing outcomes (O'Dea and Cooper, 2008). Water pricing refers to a mechanism covering the costs of different water services by making the users pay a defined sum per unit of water they used (or discharged). With cost-reflective pricing of water services, the utilities can send clear price signals to customers, allowing them to alter the pattern of consumption. Previous research emphasises the importance of the pricing mechanism in maximising water conservations across users in an urban setting (Arbues et al., 2004; Sahin et al., 2017). For example; two-part tariffs play a key role in enabling water utilities to achieve economic efficiency and cost recovery goals (OECD, 2010). Two-part tariffs will best meet the objectives of efficient pricing, cost recovery and equity for most urban water businesses (QCA, 2000).

However, traditional two-part tariff arrangements have not been linked to the water scarcity level of a particular supply region, thereby targeting high water consumers in the same manner regardless of the abundance or scarcity of water supply. Ideally, the second (or third, fourth, etc.) part of the tariff should be adjusted based on water availability or water security level. Well-advanced communications to customers will inform them of situations when their second tariff will be adjusted to reflect the water security position of the city (i.e. $60 \%$ of full supply, $40 \%$ of full supply, etc.) at the current or near-term 
projected time. When a threshold has been exceeded, the second part of the tariff can be adjusted to reflect the true cost of building and operating the capital-intensive water supply options (e.g. desalination plant) necessary to shore up water security for a city. This type of approach will ensure that capital funding is secured closer to the requirement for new infrastructure. In comparison, the current decision making approach often means that significant water security investments are only triggered during severe water scarcity situations. This approach leads to capital outlays for bulk water supply infrastructure being funded through long-term debt, meaning that customers are burdened with long-term annual price increases many years after a drought period has ended and water security has been restored. In an attempt to better link water pricing to water scarcity and equitably place the cost burden of new required bulk water supply infrastructure to those consumers that can afford to pay for higher levels of water consumption, this paper presents a novel tiered scarcity adjusted water budget and pricing structure that is argued to be preferable to water restrictions when implemented appropriately.

In many locations in Australia, water storage volumes or percentage are used as thresholds for triggering different restriction stages (Chong et al., 2009). For example, in the urban populated South East Queensland (SEQ) region, which is predominately reliant on surface water for supply, a five level restrictions schedule triggered by the dam level was introduced during the Millennium drought. For the regions' combined dam levels being 40/35/30/25/20 percent, restriction levels 1/2/3/4/5 were introduced, respectively (SEQ Water, 2015). In SEQ, water restrictions target the non-essential uses in order to reduce demand, for example: Level 1 restrictions require voluntary saving measures such as watering time; Level 2 - watering three days per week at set times by hand-held hose only; Level 3 hoses are banned with bucket watering only; Level 4 - timed bucket watering restricted to 4-8 am and 4-8 pm; and Level 5 - timed bucket watering only and vehicle washings are banned (SEQ Water, 2015).

\subsection{Tiered scarcity adjusted water budget and pricing framework}

The scarcity concept suggests that the price for a scarce good should fluctuate until reaching equilibrium between supply and demand. The concept is widely discussed/implemented by a range of industries including: online retailers (Aguirre-Rodriguez, 2013), electricity retailers (Potomac Economics, 2017) and water utilities (Denver Water, 2013). In Denver (CO, United States), water is charged progressively based on usage, with a progressive drought tariff also added when applicable per 1,000 gallons. At the peak of severe drought in 2009, the Independent Pricing and Regulatory Tribunal in Australia expressed interest in developing a scarcity pricing strategy for potential implementation in 2012 (Frontier Economics, 2011). More recently, (Lopez-Nicolas et al., 2018) have proposed a dynamic increasing block urban tariff, based on varying reservoir levels. The proposed method was designed in 2 blocks, with the first block remaining the same, while the rate of the second block varied depending on the 
storage level. However, this method didn't consider changing the block thresholds while also increasing the price of the second block.

Our work addresses this gap by taking a unified approach that combines the water consumption threshold and price, enabling upward and downward adjustment. This means that as the severity of shortage increases, the consumption threshold for Block 2 is reduced, resulting in an increase in the number of customers affected by the Block 2 price and any additional price increase. Once a water shortage is over, the higher Block 1 consumption threshold and the lower Block 2 price will be reversed to the initial level. To the best of our knowledge, this approach, termed scarcity driven tiered-pricing, accounting for both the dynamically adjusted Block 1 threshold and the Block 2 price, has not been reported to date in the literature.

Figure 1 comparatively illustrates the two key demand management strategies used to conserve urban water in times of scarcity, namely, restrictions and pricing often used to target high users through tiered structures. The authors propose a tiered scarcity adjusted water budget and pricing structure (i.e. when reaching a particular water security level, the price of water increases concomitantly). Creating a nexus between scarcity pricing and water budgets will strengthen signals to consumers, well in advance of dire water supply levels, that consumption has to be reduced to maintain water security, and that consumers willingly maintaining high levels of consumption must contribute more to the capital intensive bulk water infrastructure needed to ensure water security for the region. Such arrangement will reduce overall demand in a proactive manner while generating the required revenue to fund water security infrastructure, thereby reducing the need for long-term debt and a higher average long-run marginal cost of water. 


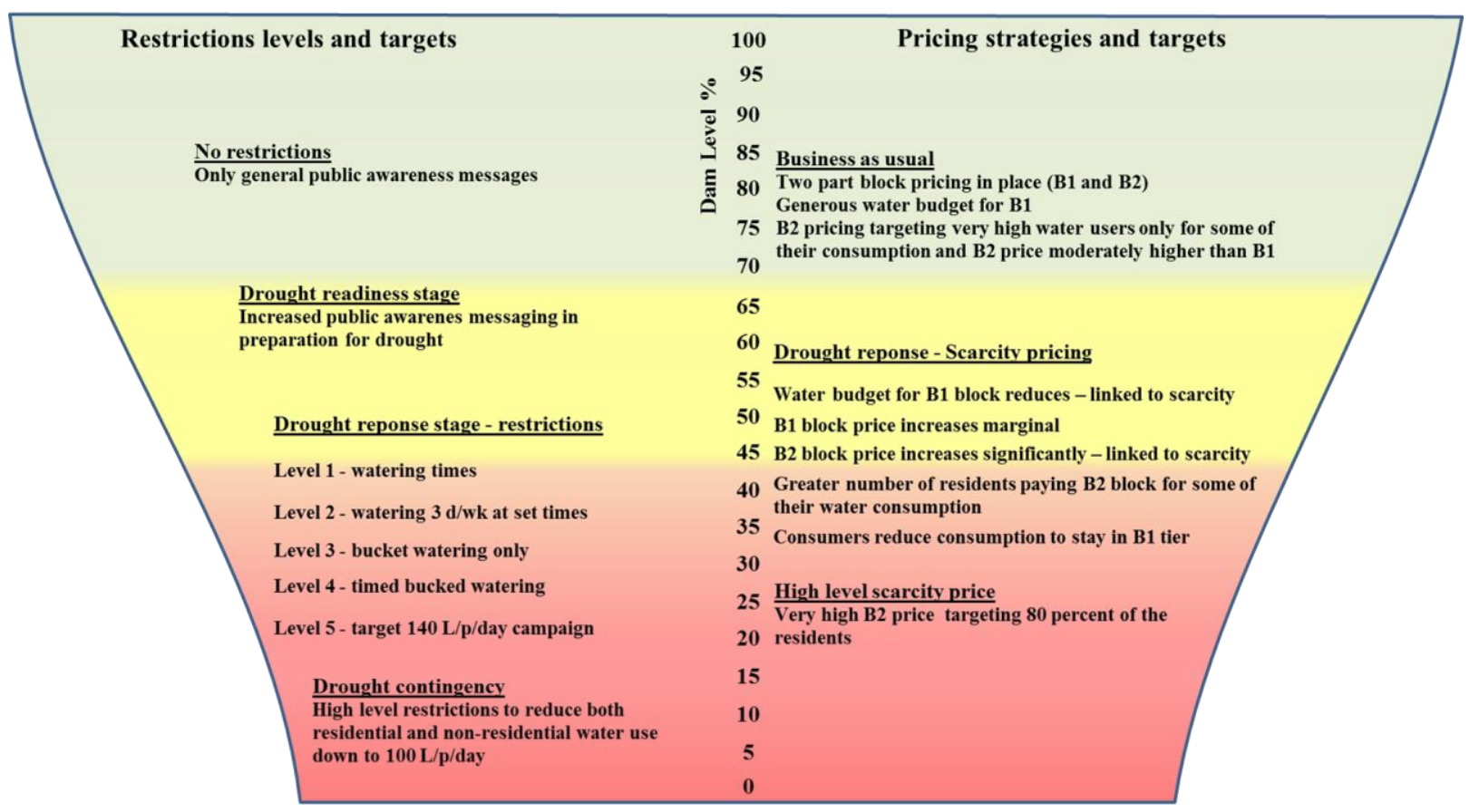

Figure 1. Comparing traditional restrictions with proposed tiered scarcity adjusted water budget and pricing structure

Restriction levels and targets on the left hand side (Figure 1) shows the approach adopted by the South East Queensland (SEQ) water authority for drought response planning (SEQ Water, 2015), which reflects the approach used across most of Australia. As an alternative to this usual restriction strategy, the authors introduce a novel tiered scarcity adjusted water budget and pricing structure as illustrated on the right hand side of Figure 1.

Restrictions require a complex set of rules for managing the water use and has been considered relatively inefficient in managing demand (O'Dea and Cooper, 2008). The Australian National Water Commission views long-term temporary restrictions as an inequitable and inefficient method (Frontier Economics, 2008). In Australia, temporary restrictions are generally focused on restricting outdoor household usage (enforced measure) coupled with behaviour change measures (i.e. social marketing), which may last for several years in some cases. For example, Permanent Water Conservation Measures were introduced across SEQ on 1 December 2009 (QWC, 2010) and revised on 21 April 2012 (QWC, 2012) to ease time-based outdoor watering restrictions, while continuing to encourage household efficiency measures.

\section{Approach}




\subsection{Systematic approach to urban water planning}

In order to tackle a range of urban water management problems, the critical factors affecting the water system and its customers, and the interactions between these factors, should be considered as an interlinked and complex feedback network. Therefore, decision makers need to adopt a suitable method to solve such a dynamic and systemic decision problem. To do so, incorporating price, supply and demand (Sahin et al., 2016), as well as all other key factors into modelling requires a dynamic approach that would provide much-needed knowledge of the future behaviour of all key factors in the system. Thus, this paper presents a novel tiered scarcity adjusted water budget and pricing framework by utilising a holistic System Dynamics Modelling (SDM) approach, and explores the advantages and disadvantages this framework compared to water restrictions, particularly when considering a range of stakeholder objectives (e.g.: equity, long run cost of water supply). The developed SDM simulates: i) the impacts of restrictions and scarcity pricing strategies on water demand; ii) the costs of restrictions to the utilities and customers; iii) the impact of a scarcity-driven tiered price scheme on customer water use and bill; and the iv) advantages and disadvantages of implementing these two strategies for customers and utilities.

\subsection{System dynamics modelling approach}

Water supply and demand systems are influenced by many interdependent components that together create a number of economic, environmental, ecological and social impacts (Loucks and van Beek, 2005). These systems, like most complex environmental systems, are highly complex and dynamic and comprising numerous feedbacks and interacting elements. Thus, SDM simulation offers an effective means of assessing water supply and demand systems by considering key factors including restriction schemes, two-part tariff, scarcity pricing, and customers' expectations.

SDM is a powerful computer simulation approach, which emerged from the management and engineering sciences (Forrester, 1961). Gradually, the SD approach has evolved and spread into other fields to simulate complex systems behaviour. Some examples include: planning environmental management system in Erhai Basin in China (Guo et al., 2001); a SDM as an experimental platform for examining long-term environmental impacts of the South-eastern Anatolian Project (in Turkey) on water resources, land use, land degradation, agricultural pollution and demography (Saysel et al., 2002); estimating $\mathrm{CO}_{2}$ emissions from the cement industry in India (Anand et al., 2006); a SDM as an education tool for teaching public and students the implications of common water management alternatives in order to increase public awareness (Williams et al., 2009); a model for understanding the relationship between water demand and macroeconomic environment for long-term municipal water demand forecasts (Qi and Chang, 2011); a model for informing policy-makers seeking to undertake long term planning of water supply augmentation decisions (Porter et al., 2014); and a model for exploring long 
term water supply planning strategies by incorporating economic, social and environmental factors (Scarborough et al., 2015).

SDM is an approach focusing on the behaviour of complex systems, which change over time and contain many feedback loops and time delays affecting the behaviour of the whole system. Feedback loops are closed sequences of causes and effects, or, a closed path of action and information (Kirkwood, 1998). These feedback loops are often linked together and display nonlinear relationships that often cause counterintuitive behaviours. The SDM approach assumes that all systems have the same fundamental structure of accumulations and flows structured into feedback loops that cause all changes through time (Forrester, 1994). Kelly et al. (2013) presented some useful examples of how SDM and other systems approaches have been utilised in exploring complex interactions between humans and ecosystems.

\subsection{Situational and stakeholder engagement context}

The SDM scenarios presented in this paper were based on residential water consumption data and existing tariff structures for a medium-sized urban city. The city has a predominantly surface-fed water supply but also relies on climate-independent sources such as desalination and recycled water due to historically variable rainfall patterns in the region. The city has a progressive local authority that has adopted novel smart metering projects along with recent tariff reform and heightened customer engagement strategies. These initiatives have provided an excellent source of both qualitative and quantitative datasets that have underpinned a range of applied research projects such as: impact of sociodemographic factors and efficient devices on water consumption in households (Willis et al., 2013); rainwater tank systems (Gurung and Sharma, 2014); and water heaters in residential buildings (Vieira et al., 2015).

Most recently, Sahin et al. (2017) reported on a body of work that involved a mix methods approach focussed on applying SDM scenarios to inform suitable demand-based tariff options. As part of that work, two of project stakeholder groups were formed to maintain strong and appropriate engagement with relevant stakeholders (Table 1). The Project Reference Group (PRG) comprised of representatives from relevant stakeholder groups such as the Queensland Council of Social Service (QCOSS), the cities' Ratepayers Association, local councillors and relevant officers within the local water authority. The role of the PRG was only to provide advice on options and recommendations arising from the research. Meetings with the PRG before, during and near completion of the research ensured that stakeholders remain informed of the progress and outcomes of the project. A Project Management Group (PMG) involving the key experts from the water utility and the research team was also established. The role of the PMG was to provide technical and strategic advice on the SDM design and implementation. Section 2.3 describes how the PRG and PMG were influential in providing a participatory modelling approach. 
Table 1. Stakeholder representatives and roles for participatory SDM formulation

\begin{tabular}{|c|c|c|c|}
\hline Group & Stakeholder & Position/s & Role in group \\
\hline Project & City council & Water authority manager & Observer \\
\hline \multirow[t]{3}{*}{$\begin{array}{l}\text { Reference } \\
\text { Group (PRG) }\end{array}$} & City council & $\begin{array}{l}\text { City councillors representing } \\
\text { the electorates that will be } \\
\text { impacted from tariff reform }\end{array}$ & Chair PRG and represent city constituents \\
\hline & $\begin{array}{l}\text { Qld Council or } \\
\text { Social Services } \\
\text { (QCOSS) }\end{array}$ & $\begin{array}{l}\text { Senior Policy Officer in } \\
\text { Practice, Research and Policy }\end{array}$ & $\begin{array}{l}\text { Represent equity and fairness amongst } \\
\text { the range of socio-demographic } \\
\text { categories }\end{array}$ \\
\hline & $\begin{array}{l}\text { Technical and Social } \\
\text { Science experts }\end{array}$ & $\begin{array}{l}\text { Academics in the field of } \\
\text { engineering and social science } \\
\text { from Griffith University }\end{array}$ & $\begin{array}{l}\text { Establish applied research baselines to } \\
\text { underpin modelling and } \\
\text { recommendations }\end{array}$ \\
\hline \multirow{6}{*}{$\begin{array}{l}\text { Project } \\
\text { Management } \\
\text { Group (PMG) }\end{array}$} & Griffith University & Systems Modeller, & To integrate expertise and technical \\
\hline & & $\begin{array}{l}\text { Environmental Scientist, } \\
\text { Social Scientist and } \\
\text { Engineering researchers }\end{array}$ & $\begin{array}{l}\text { knowledge into participatory SDM } \\
\text { approach (e.g. water use data, modelling, } \\
\text { willingness to pay surveys) }\end{array}$ \\
\hline & City council & Gold Coast Water Manager & $\begin{array}{l}\text { Provide strategic input into the SDM } \\
\text { design and outcomes }\end{array}$ \\
\hline & City council & $\begin{array}{l}\text { Co-ordinator, Demand } \\
\text { Management }\end{array}$ & $\begin{array}{l}\text { Provide input into city residential water } \\
\text { demand patterns }\end{array}$ \\
\hline & City council & $\begin{array}{l}\text { Co-ordinator, Pricing and } \\
\text { Regulation }\end{array}$ & $\begin{array}{l}\text { Provide economic and tariff reform } \\
\text { advice for the city }\end{array}$ \\
\hline & City council & $\begin{array}{l}\text { Executive Co-ordinator } \\
\text { Revenue Services }\end{array}$ & $\begin{array}{l}\text { Provide input into structure and } \\
\text { implementation of tariff reform }\end{array}$ \\
\hline
\end{tabular}

\subsection{Model development process}

As illustrated in Figure 2, in order to establish consensus regarding the problem to be modelled (Vennix et al., 1996), a five-step participatory modelling approach was utilised to ensure a realistic replication of the system structure so that modelling would reveal system behaviour, which is often far from what initial intuition would suggest (Van den Belt et al., 2004; Langsdale et al., 2009). The participatory approach requires adequate and ongoing consultation and/or direct involvement of key stakeholders, which is essential in identifying demand management strategies, evaluating risk and making relevant and appropriate decisions. The stakeholders' participation will ensure a clear understanding of how the proposed changes would affect the availability of resources and services. Therefore, a key first step activity for the PRG was to provide input into the SD model development including design and scenario scoping. 


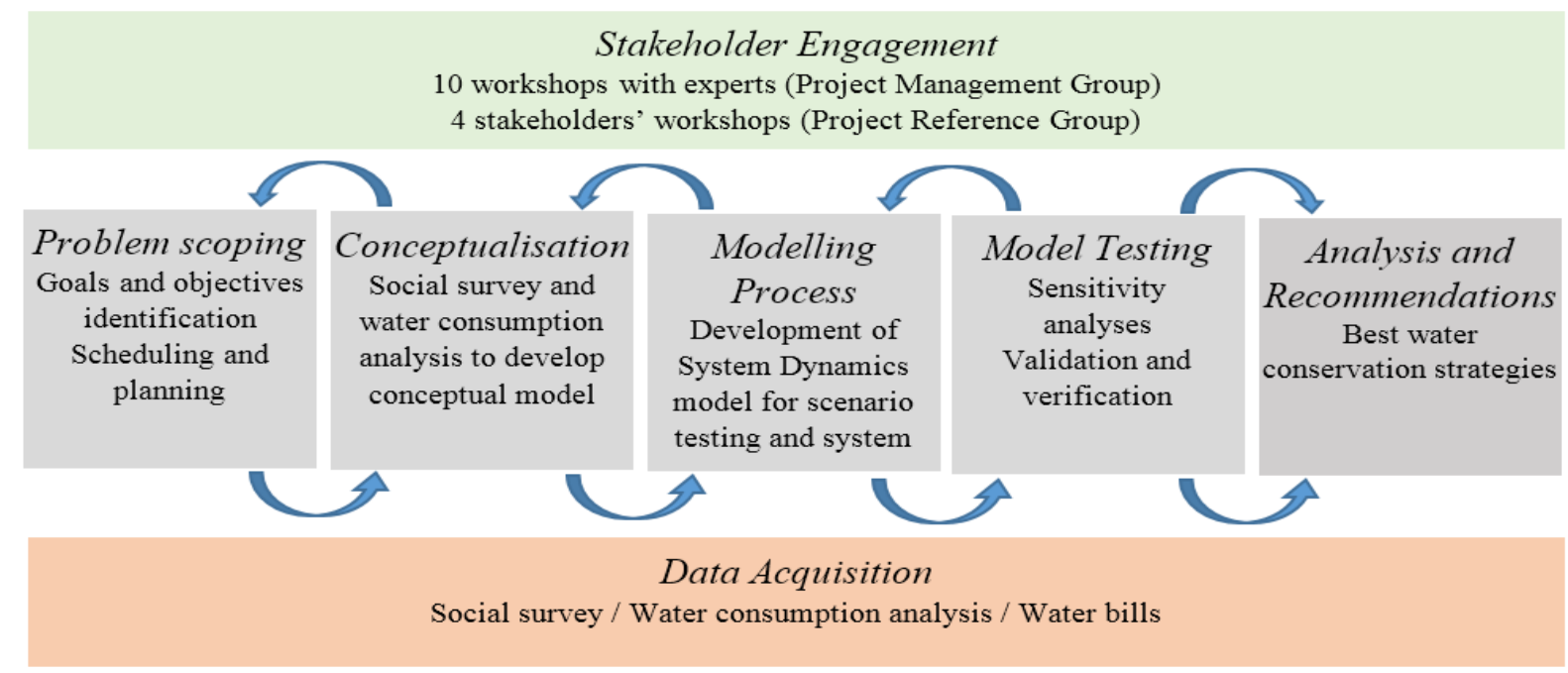

Figure 2. Key steps for stakeholder participation and building a SD model

Throughout the project, fourteen PMG and PRG workshops were conducted, during which the stakeholders were involved in the model development, calibration and testing process. During the scope definition workshop, key research questions, the related assumptions and variables were determined and relationships between these variables were parameterised. These workshops also allowed for refining the model outputs to ensure that they were accurate and provided evidence-based support for any water pricing reforms that might be considered by the city.

Key variables for SDM and their causal relationships were identified by reviewing the literature, consultation with the city staff and focused workshops. The Causal Loop Diagram (CLD) in Figure 3 illustrates cause and effect relationships between variables of a simple water supply and demand system. The arrows and plus/minus signs at the end of the arrows show the causality and polarity of the relationships between these variables. For example, when the variable "Water Supply" changes, the variable at the end of the arrow with (-) sign changes in the opposite direction, which indicates that an increase in "Water Supply" would result a decrease in "Supply Demand Gap". On the other hand, when "Supply Demand Gap" changes (e.g. increases), then the need for "Water Supply" will change in the same direction (e.g. increase). The capital " $\mathrm{B}$ " and " $\mathrm{R}$ " signs in the loops tell whether it is a balancing (goal seeking behaviour) or a reinforcing (changes leads to even more changes) feedback loop. 


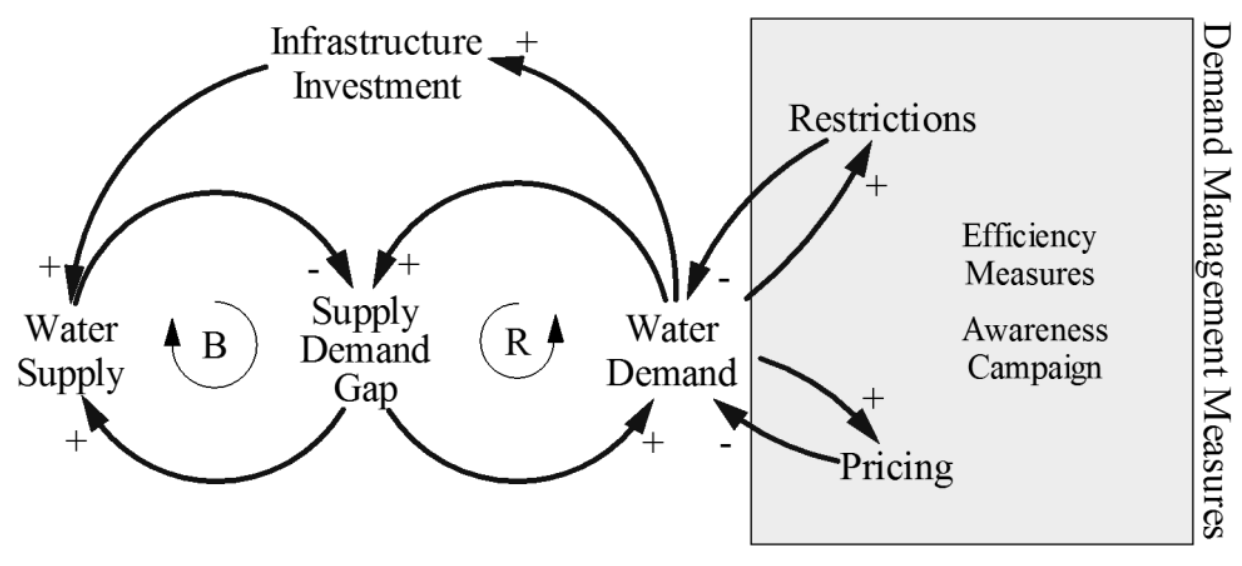

Figure 3. A basic feedback structure showing the causal relationships between a water supply and demand system

\subsubsection{Social survey and end-user analysis}

A social research survey was developed to provide a systematic assessment of the case study city residential customers' water billing preferences. Individual computer assisted telephone interviews (CATI) were conducted with 800 randomly selected homeowners within the city. This represents a response rate of 12 percent for the 9,000 homes contacted. Participants were asked about their preferences for fixed and variable charges. The findings from this survey provided a clear picture of customers' understanding and preferences of their water billing structures and willingness to use and pay for their water during times of water shortages. Taken together, the overall results of the social analysis research were used as inputs to the SDM (Sahin et al., 2017).

Another critical input into the SDM was the high-resolution smart metering water consumption data for residential properties in the city (Beal and Stewart, 2011). This data provided a 'ground truthing' for the variability of water use patterns amongst city homes, which in turn enabled realistic and relevant scenarios to be generated. For example, the changes (increases) to outdoor water use measured following an easing of water restrictions in SEQ, provided invaluable insight into the likelihood and degree of rebounding demand with and without restrictions in place. Similarly, matching sociodemographic data with observed water demand, enabled greater accuracy in predicting the social impact of tariff rises for high water users in the city.

\subsubsection{Baseline assumptions and scenarios}

The water charges used to calculate a typical household bill in the study region and some key assumptions used in the SDM are provided in Table 2.

Table 2. Key assumptions and input data for the SDM 


\begin{tabular}{|c|c|}
\hline Variable & Input data \\
\hline Fixed sewerage charges ${ }^{1,2}$ & AUD\$ 725.12 household/year (hh/y) \\
\hline Fixed water charges ${ }^{1,2}$ & AUD\$ $212.08 \mathrm{hh} / \mathrm{y}$ \\
\hline Volumetric water consumption charges ${ }^{1,2}$ & AUD\$ 3.53 per kL \\
\hline Price Elasticity & Ranging from -0.3 to $-0.8 /$ Default $=-0.51$ \\
\hline Number of water consumption segments & 16 \\
\hline Model time bound & 10 years (120 months) \\
\hline Simulation time step & Month \\
\hline Average water use per capita (kL/year) ${ }^{2}$ & 163 \\
\hline
\end{tabular}

As shown in Table 3, based on a 3-year individual billing data (2013-2015) obtained from the case study city water utility department, sixteen customer segments were created and used to project the average water bill for each segment. These served as baseline assumptions when simulating the impact of tariff options on shifting the water usage of customer segment and associated water bill. For example, a customer located in the 160 - $180 \mathrm{~kL}$ segment may be shifted to the $140-160 \mathrm{~kL}$ segment due to a price-, or restriction-, driven water-use reduction.

Table 3. Proportion of each customer segment and their aggregated water consumption

\begin{tabular}{|c|c|c|c|c|c|c|c|c|c|c|c|c|c|c|c|c|}
\hline $\begin{array}{l}\text { Customer } \\
\text { segments }\end{array}$ & $\begin{array}{l}\stackrel{0}{\hat{~}} \\
\frac{\vec{\partial}}{\hat{\theta}} \\
\stackrel{+}{+}\end{array}$ & $\begin{array}{l}\stackrel{q}{+} \\
\hat{A} \\
\hat{\vec{\theta}} \\
\hat{\hat{\theta}}\end{array}$ & $\begin{array}{l}\stackrel{\otimes}{D} \\
\hat{A} \\
\hat{\vec{y}} \\
\hat{\hat{O}}\end{array}$ & 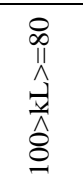 & 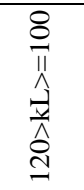 & 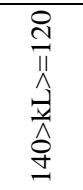 & 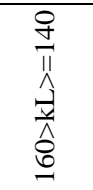 & 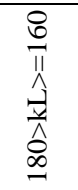 & 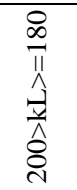 & 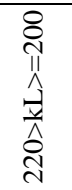 & 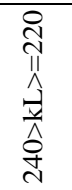 & 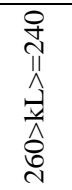 & 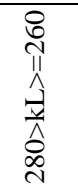 & 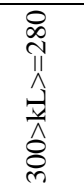 & 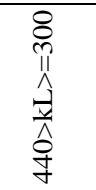 & $\begin{array}{l}\stackrel{O}{J} \\
\| 1 \\
\hat{a} \\
\underline{\underline{v}}\end{array}$ \\
\hline Usage $(\%)$ & $0.4 \%$ & $1.1 \%$ & $3.2 \%$ & $6.4 \%$ & $8.6 \%$ & $9.8 \%$ & $10.1 \%$ & $8.9 \%$ & $7.9 \%$ & $6.6 \%$ & $5.4 \%$ & $4.5 \%$ & $3.5 \%$ & $2.8 \%$ & $10.4 \%$ & $10.3 \%$ \\
\hline Users (\%) & $3.6 \%$ & $3.7 \%$ & $7.3 \%$ & $11.6 \%$ & $12.8 \%$ & $12.3 \%$ & $10.9 \%$ & $8.6 \%$ & $6.8 \%$ & $5.1 \%$ & $3.8 \%$ & $3.0 \%$ & $2.1 \%$ & $1.5 \%$ & $4.8 \%$ & $2.2 \%$ \\
\hline
\end{tabular}

Independent Pricing and Regulatory Tribunal (IPART) modelling in Australia indicates that, in order to imitate a demand reduction achieved through level-3 water restriction, prices would need to rise by a minimum 57 per cent (O’Dea and Cooper, 2008). This equates to about a \$5.5 AUD dollars per kilolitre $(\$ / \mathrm{kL})$ price level and this value was used for calculating Block 2 charges under Scenario 2 and Scenario 3 as presented in Table 4. In this research, the price elasticity of demand (PED) was assumed to be -0.51 after a critical review of the literature. For example; a study, based on earlier analyses of 124 estimates generated between the years 1963 and 1993, suggests that the mean price elasticity is -0.51 , the short-run median is -0.38 , and the long-run median is -0.64 , with 90 per cent of all estimates between 0 and -0.75 (Olmstead et al., 2007). Another study (Hoffmann et al., 2006) in 2016 estimates a price elasticity of residential water demand equal to -0.507 for Brisbane, Australia. Accordingly, the SDM is designed to simulate the impacts of different levels of elasticity on demand by enabling the elasticity to vary between -0.3 to -0.8 . In order to analyse the impact of price on water consumption, an increasing block tariff (IBT) in which a first block (B1) representing the basic water use at a lower price and second block (B2) representing higher rates of water use was considered. The 
impacts of dynamic pricing in which the prices for the $\mathrm{B} 1$ relative to the $\mathrm{B} 2$ were adjusted based on the severity of the water shortage were also analysed. It must be noted that the B1 price elasticity for each scenario is set to zero. This means that the customers below the B1 consumption threshold will not be affected by a price increase.

Each simulation runs over a 10-year period in order to observe the long term impact of pricing and restriction measures on demand and revenue. This equated to 40 quarterly (i.e. 3 month -4 per year) billing cycles; quarterly billing aligned with the actual billing cycles used in the case study city and more widely across SEQ, Australia. The model also considers rebounding demand over a 'rebounding time' with an assumption that an increase in water price will result in a gradual decrease in demand, depending on price elasticity. The 'rebounding time' refers to the period of time over which the rebound in water consumption demand occurs. After which, assuming no further price increase during this period, the consumers would adjust their consumption level (demand) back to the original level. After consultations with the utility's experts, the time 'lag' for adjusting demand was assumed to be 2-4 billing periods (about $6-12$ months), while the rebounding time was assumed to be 6-8 billing periods (18-24 months) based on information available for recent droughts in Australia (QWC, 2010).

The SDM allows a flexible scenario development approach, which enables users to modify key variables in the model to test a large number of scenarios by using simulation techniques. To examine the impacts of the key strategies on the water price-demand revenue system, 5 predefined scenarios (Scn) were explored (Table 4).

Table 4. Water restriction and pricing scenarios

\begin{tabular}{llllll}
\hline Variable description & Scn1 & Scn2 & Scn3 & Scn4 & Scn5 \\
\hline Proportion of B1 customers $(\%)$ & 100 & 80 & 50 & 20 & 100 \\
B1 cut off $(\mathrm{kL} / \mathrm{hh} / \mathrm{y})$ & $\mathrm{n} / \mathrm{a}$ & 296 & 172 & 112 & $\mathrm{n} / \mathrm{a}$ \\
Price elasticity & $\mathrm{n} / \mathrm{a}$ & -0.51 & -0.51 & -0.51 & $\mathrm{n} / \mathrm{a}$ \\
B1 Price $(\$ / \mathrm{kL})$ & 3.53 & 3.53 & 3.53 & 3.53 & 3.53 \\
B2 Price $(\$ / \mathrm{kL})$ & $\mathrm{n} / \mathrm{a}$ & 5.5 & 5.5 & 5.5 & $\mathrm{n} / \mathrm{a}$ \\
Restriction level & $\mathrm{n} / \mathrm{a}$ & $\mathrm{n} / \mathrm{a}$ & $\mathrm{n} / \mathrm{a}$ & $\mathrm{n} / \mathrm{a}$ & $3-5$ \\
\hline
\end{tabular}

Scn1 represents business as usual (BAU) conditions and provides a baseline scenario from which comparisons are made. Scn2-Scn4 scenarios explore three different scarcity-driven two-part tariff conditions. Scn2 -Scn4, includes the sewerage, volumetric and fixed water charges. Scn2 represents a condition that there is no water shortage and the water utility adopts a two-part tariff in order to implement a "user pays" strategy targeting top 20 percent of residential water customers. Scn3 represents a moderate drought condition under which water utility reduces the Block 2 threshold, having the effect to reduce customer demand through pricing with up to $50 \%$ having a proportion of their consumption priced in $\mathrm{B} 2$. The $\mathrm{Scn} 3$ price level is set to achieve a demand reduction equal to $15 \%$, 
which is the goal of the level-3 restriction target. Scn4 represents a severe drought condition. At the time of this research, the utility implements a much higher scarcity price affecting a high proportion of water customers for some of their consumption, however, the lowest consumers (e.g. elderly couple) will still remain within $\mathrm{B} 1$ for all of their consumption. Scn 4 aims to achieve a $25 \%$ demand reduction, which equates to a level-5 target. Under these three scenarios (i.e. Scn2-Scn4), it is assumed that only those customers who use a large volume of water will incur this higher volumetric price (i.e. B2 price) for the majority of their consumption. The remainder will incur only a small proportion or no consumption at the B2 pricing rate. Three priced based scenarios simulate the impact of a dynamic pricing strategy by adjusting the B1 cut off points based on the severity of the water shortage. Scn5 simulates restriction-imposed conditions. That is, Scn5 disregards any pricing strategy and instead, imposes the restrictions on water use based on the severity of the water shortage.

\subsubsection{SDM formulation}

To simulate the water resources system in the case study region, an SDM (Figure 4) was built using Vensim® DSS (Ventana Systems, 2018). The SDM was informed by; (1) data/opinion obtained from the city staff and PRG; (2) the social research survey specifically developed to provide a systematic assessment of city residential customers' water billing preferences; and (3) the South East Queensland Residential End-Use Study (SEQREUS) data (Beal and Stewart, 2011). The SDM was first developed and applied in SEQ to explore scarcity pricing (Sahin et al., 2015) and potential of pressure retarded osmosis (PRO) technology to generate electricity (Sahin et al., 2016). It was subsequently modified to develop two models for Melbourne (Porter et al., 2014; Scarborough et al., 2015) to explore rain independent versus rain dependent water resources in long-term planning. Finally, the SDM was adjusted to examine economic and social implications of demand-based tariff structures and their potential for greater water conservation (Sahin et al., 2017). For this research, the generalised model used in previous studies has been customised for assessing various demand management strategies, particularly the impacts of implementing restrictions and novel dynamic scarcity pricing strategies on customers and utilities. 


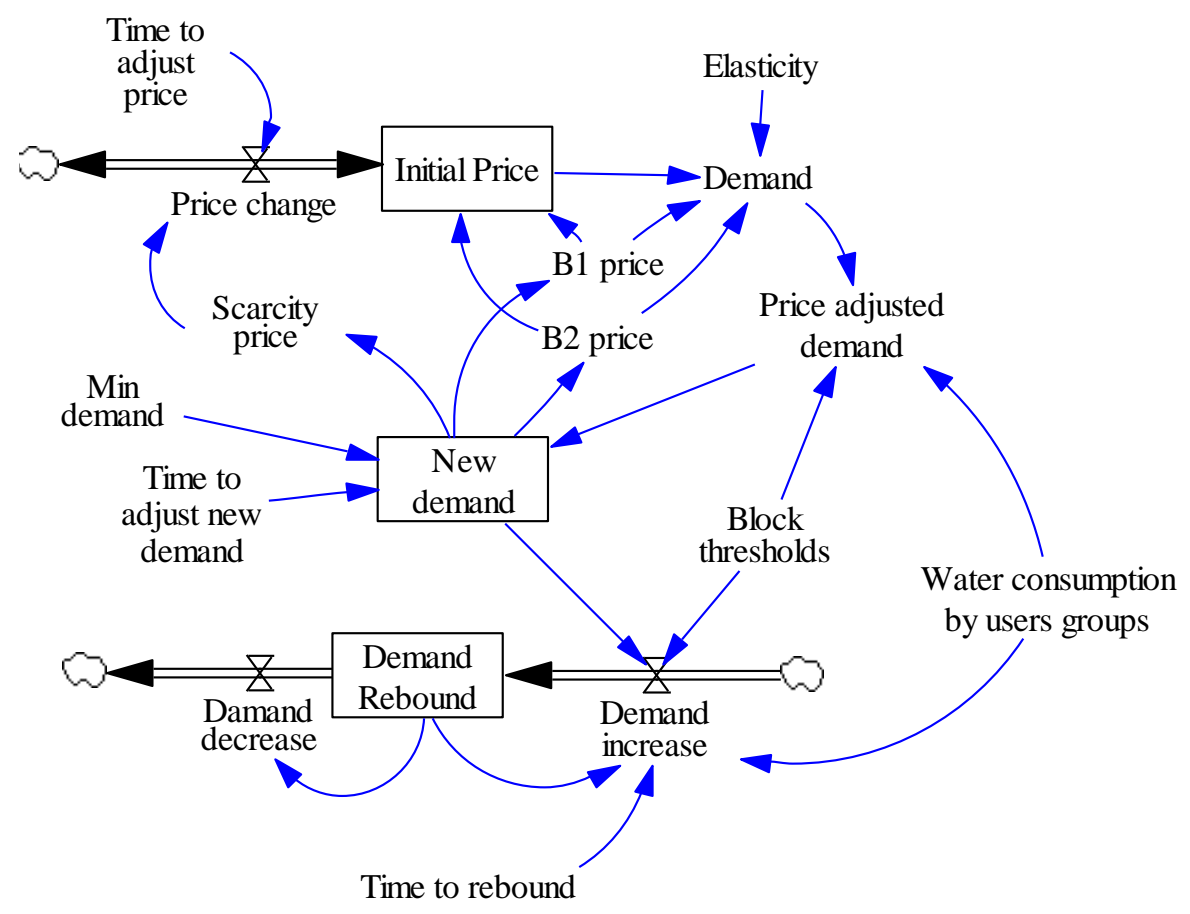

Figure 4. Stock and flow SDM diagram showing price-based water demand mechanism

The SDM in Figure 4 illustrates the strong interdependencies between price levels and water demand, which in turn influences water demand, supply, and finance (i.e. pricing, revenue, investment etc.). The population growth rate, the scale of price change, water consumption thresholds for tariff blocks (B1 and B2) would significantly affect both supply need and demand for water over time. For example, using the following equation, the changes in water consumption resulting from the customers' response to a price change was calculated:

Change in demand $=R D \times(P / R P)^{E d}$

Where: $R D$ represents the average water consumption level of the each customer segment, $P$ refers to the new water price level, $R P$ represents the initial water price level and $E d$ shows the demand elasticity.

The model evaluation (calibration/validation) process involved fine-tuning the model to a particular context by establishing a unique set of parameters that measure the model to its data (Crooks et al., 2008). However, there is no consensus among modellers as to what the procedures for evaluating models should be. This is simply because complex systems are dynamic and change unpredictably. According to Oreskes (2004), verification and validation of numerical models of natural (open) systems are impossible. To address these problems, Sojda (2007) proposed a 5-step evaluation method: (1) testing model against a preselected standard; (2) use of historic datasets for comparison with simulated 
output; (3) expert judgements; (4) sensitivity analysis; and (5) focusing on key model elements if the validation of an entire system is not possible to identify probable drawbacks. Similarly, Bennett et al. (2013) proposed a five-step evaluation method for model performance: (1) reviewing the models scope; (2) characterisation of the data for calibration and testing; (3) visual inspection to spot unexpected model behaviour; (4) selection of basic performance criteria; and (5) use of advanced methods such as systematic divergence between modelled and observed values.

In the field of system dynamics, discussions of validation have highlighted three key points: there can be i) no absolute test of validity; ii) no objective test of validity; and iii) no single test of validity (Sterman, 1984). Therefore, the modellers focus on building confidence in a model rather than comparing their models to historical data or a single test. This concept is well documented in the SD literature. For example the founder of system dynamics, Jay Forrester, states that a model cannot be expected to have absolute validity (Forrester, 1968); Barlas and Carpenter (1990) argue that model validation is inherently a social, judgmental, and qualitative process. Thus, models cannot be proved valid but can be judged instead. Therefore, validation includes the communication process in which the modeller must communicate the bases for confidence in a model to stakeholders (end users) (Forrester and Senge, 1980).

Considering the discussion above, this paper adopted a 5 step model evaluation process:

1. Engaging multi stakeholders throughout modelling process was undertaken as outlined in Table 1. To achieve an agreed final model, the initial model (SDM v1) was modified and tested a number of times through stakeholder workshops and expert consultations before the final model (SDM v10) was confirmed. Involvement of stakeholders throughout the modelling process ensured the model output adequately reflects the real situation by adjusting the modelling scope and modelling logic (i.e. parameter relationships). As a result, the model was significantly improved in terms of its usefulness. The stakeholders' agreement on the model was an essential step to check whether the built model was realistic enough in addressing its intended purpose.

2. Input parameter validation was achieved by using three years of individual billing data and historical reservoir data for the case study city. A backward forecast comparing the output of the simulation with actual historical records was completed.

3. Comparing the model output with the water utilities and other stakeholders' past internal reports. As Huggett (1993) suggests, it is sound practice to test the validity of a model by comparing its prediction with independent observations made in the field or laboratory.

4. By presenting the model to stakeholders at outcomes workshops for visual inspection and observing whether the model logic convincingly predicted expected behaviours of the system. 
5. Sensitivity analysis was performed for key input variables to explore whether their adjustment had excessive or unexpected influence on output variables.

\section{RESULTS AND DISCUSSION}

\subsection{Social research survey}

The majority of respondents (over 50 percent) indicated that they would prefer a lower fixed water access charge and a higher usage charge. Approximately 52 percent respondents were supportive or extremely supportive of a "two-step" pricing approach where very high water users would pay more for water than low to average water users. Just over 25 percent were neutral, over six percent were somewhat supportive, and 16 percent were not at all supportive of this approach. When asked what proportion of customers should be targeted for the second step (higher price), 34 percent said "high water users", over 26 percent said "only very high water users", and over 22 percent of respondents said "only extremely high water users". Participants were asked about their preferences during dry periods, when water supplies are getting low. Almost all of the respondents (93 percent) stated that they would be comfortable to stay within set water restrictions to conserve supplies. When asked about their preferences if there were no restrictions, but only a higher water price during periods of low water supply, the majority of respondents ( 80 percent) said they would prefer that the higher water price is charged only for high water use during those periods. The findings regarding customers' preferences for water restrictions over the option to use water at a higher price during dry periods are at odds with current literature which suggests that people are willing to pay more for water during these times (Sahin et al., 2016). The city customers' current attitudes a carry-over from the recent Millennium drought and the highly effective Target 140 communications campaign in the region (Walton and Hume, 2011).

Indoor and outdoor water consumption patterns during the period of drought was presented in Beal and Stewart (2011). A subsequent study by Beal and Stewart (2014) reported a measured increase in outdoor water use following an easing of water restrictions in the city and SEQ in general. Residential water demand increased from 145 litres per person per day (L/p/d) to $201 \mathrm{~L} / \mathrm{p} / \mathrm{d}$ between 2010 and 2012, mainly driven by an increase in outdoor water use activities (Beal and Stewart, 2014). This information provides some insight into the likelihood and degree of rebounding demand with and without restrictions in place.

\subsection{SDM scenario analysis}

Three major water use categories were established from the cities' billing data (from which the frequency distribution curve was developed) and the SEQREUS data (from which the household characteristics were averaged for low, average and high water use groups). Average annual water 
consumption for low, medium and high water groups are 110, 170 and $290 \mathrm{~kL} / \mathrm{hh} / \mathrm{year}$, respectively. Low water users represent almost 40 percent of the customers and only 20 percent of the total consumption. This information allows the identification of household groups that are likely to be the most and least responsive and/or affected by pricing and restriction measures. Based on water end-use analysis of the city households (Beal and Stewart, 2011), the very high water use groups $(>290$ $\mathrm{kL} / \mathrm{hh} /$ year) use a higher percentage of water for outdoor use, and are likely to be from larger families with higher household incomes than the lower water use groups.

The comparison of quarterly water bills for these three water use groups under 5 scenarios is shown in Figure 5. Under Scn5, which represents restriction strategies (Table 4), all groups' bills were decreased by $6-11$ percent (low and high users) as their water consumption decreased due to restriction measures. However, due to fixed charges, a decrease in water consumption of low water users has a much smaller impact on their water bills compared to the high water users'. Under Scn2, 3 and 4, the lower water users are not affected by a price increase while average and high water users would start to pay more for their water use. The average water users pay about 7 percent more while the high water users pay 18 percent more. Through the pricing approach, which targets specific customers based on their water consumption, water utilities would be able to implement more effective, equitable and dynamic water pricing strategies as demonstrated in Table 5. The equity refers to a water tariff that treats similar customer groups equally, that is, customers' quarterly bills would be proportionate to their water use. In this respect, feedback from the PRG workshops and from QCOSS in particular, confirmed that tariff equity is an important stakeholder consideration that needs to be implicit in any city tariff restructuring.

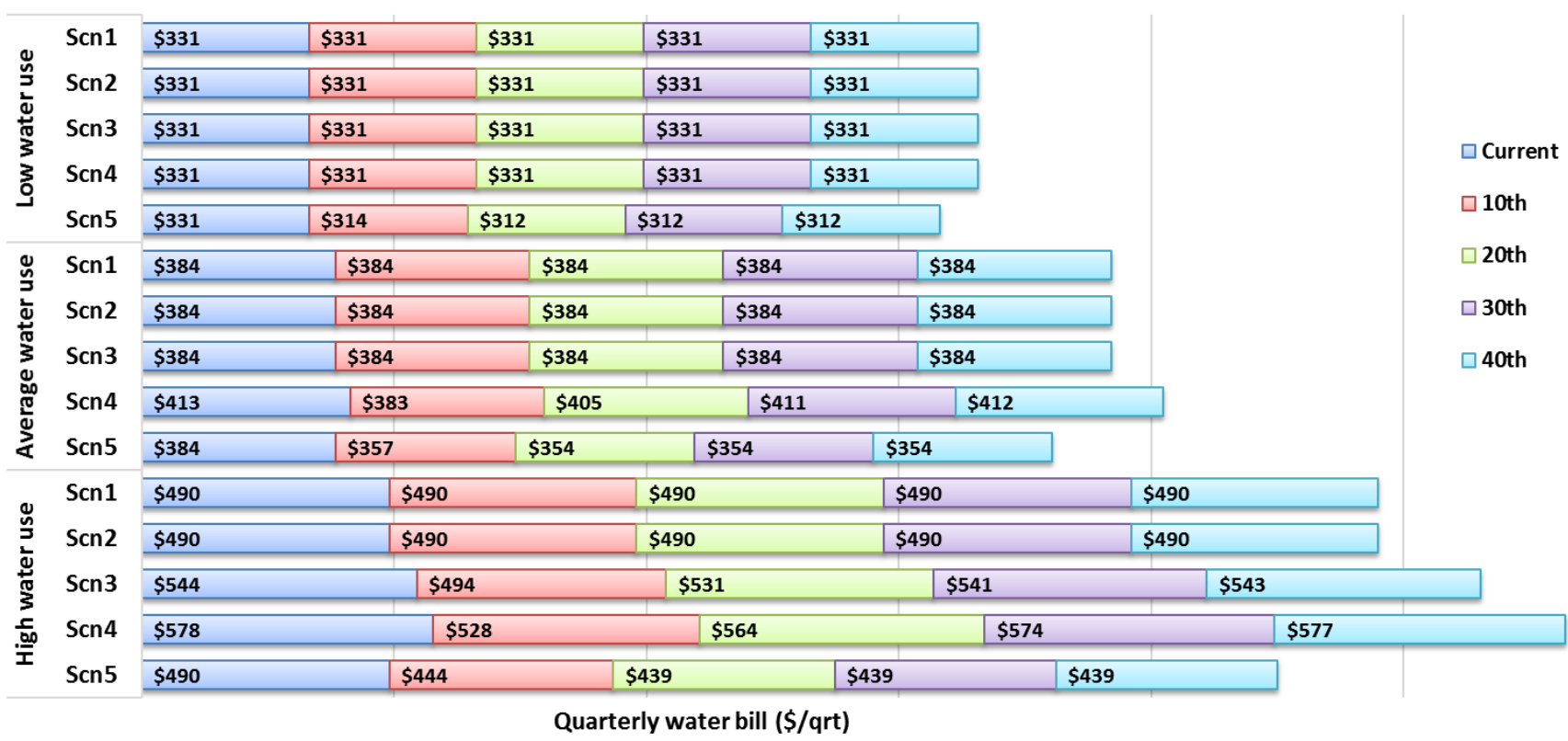

Figure 5. Comparison of simulated quarterly water bills (\$) for three consumption levels 
Further, the use of a uniform pricing or an inclining two-part block tariff ( $\operatorname{Scn} 1$ and $S c n 2$ ) are also important as elasticities and resulting demand under uniform and tiered rates may vary. For instance, a study in 2015 reports that the elasticity in East Los Angeles and South San Francisco were -0.39 to 0.22 under uniform rates and -0.44 and 0.43 under tiered rates, respectively (Lee and Tanverakul, 2015). This means that a scarcity pricing strategy would be more effective if combined with two-part tariffs in order to implement a flexible scarcity-driven pricing. As shown in Figure 5 and Table 5, the proposed pricing mechanism would be more effective in fully addressing the equity considerations as it mainly targets high water users and ensures water supply remains affordable for low income water users. This can be achieved by a dynamic scarcity-driven two-part tariff mechanism, where a low price would apply to the first block of consumption and a high scarcity price would apply to consumption above this level.

Table 5. Changes in water bill and consumption under five scenarios (high water use segment)

\begin{tabular}{rcccccccccc}
\hline \multirow{2}{*}{$\begin{array}{c}\text { Billing } \\
\text { cycles }\end{array}$} & \multicolumn{2}{c}{ Scn1 } & \multicolumn{2}{c}{ Scn2 } & \multicolumn{2}{c}{ Scn3 } & \multicolumn{2}{c}{ Scn4 } & \multicolumn{2}{c}{ Scn5 } \\
\cline { 2 - 11 } & $\begin{array}{c}\text { Water use } \\
(\mathrm{kL} / \mathrm{qrt})\end{array}$ & $\begin{array}{c}\text { Bill } \\
(\$ / \mathrm{qrt})\end{array}$ & $\begin{array}{c}\text { Water use } \\
(\mathrm{kL} / \mathrm{qrt})\end{array}$ & $\begin{array}{c}\text { Bill } \\
(\$ / \mathrm{qrt})\end{array}$ & $\begin{array}{c}\text { Water use } \\
(\mathrm{kL} / \mathrm{qrt})\end{array}$ & $\begin{array}{c}\text { Bill } \\
(\$ / \mathrm{qrt})\end{array}$ & $\begin{array}{c}\text { Water use } \\
(\mathrm{kL} / \mathrm{qrt})\end{array}$ & $\begin{array}{c}\text { Bill } \\
(\$ / \mathrm{qrt})\end{array}$ & $\begin{array}{c}\text { Water use } \\
(\mathrm{kL} / \mathrm{qrt})\end{array}$ & $\begin{array}{c}\text { Bill } \\
(\$ / \mathrm{qrt})\end{array}$ \\
\hline Current & 73 & $\$ 490$ & 73 & $\$ 490$ & 73 & $\$ 544$ & 73 & $\$ 578$ & 72 & $\$ 490$ \\
10 th & 73 & $\$ 490$ & 73 & $\$ 490$ & 63 & $\$ 494$ & 63 & $\$ 528$ & 59 & $\$ 444$ \\
20 th & 73 & $\$ 490$ & 73 & $\$ 490$ & 70 & $\$ 531$ & 70 & $\$ 564$ & 58 & $\$ 439$ \\
30 th & 73 & $\$ 490$ & 73 & $\$ 490$ & 72 & $\$ 541$ & 72 & $\$ 574$ & 58 & $\$ 439$ \\
40 th & 73 & $\$ 490$ & 73 & $\$ 490$ & 72 & $\$ 543$ & 72 & $\$ 577$ & 58 & $\$ 439$ \\
\hline
\end{tabular}

The price increase signals that the customers should reduce their demand through a range of physical and behavioural measures. In the case of restrictions, this reduction in demand also reduces revenues. This means that a well-targeted scarcity-driven pricing would generate the surplus revenues to provide the much-needed capital funding for future infrastructure investments and maintenance (Figure 6).

$\square \operatorname{Scn} 1 \square \operatorname{Scn} 2 \square \operatorname{Scn} 3 \square \operatorname{Scn} 4 \square \operatorname{Scn} 5$

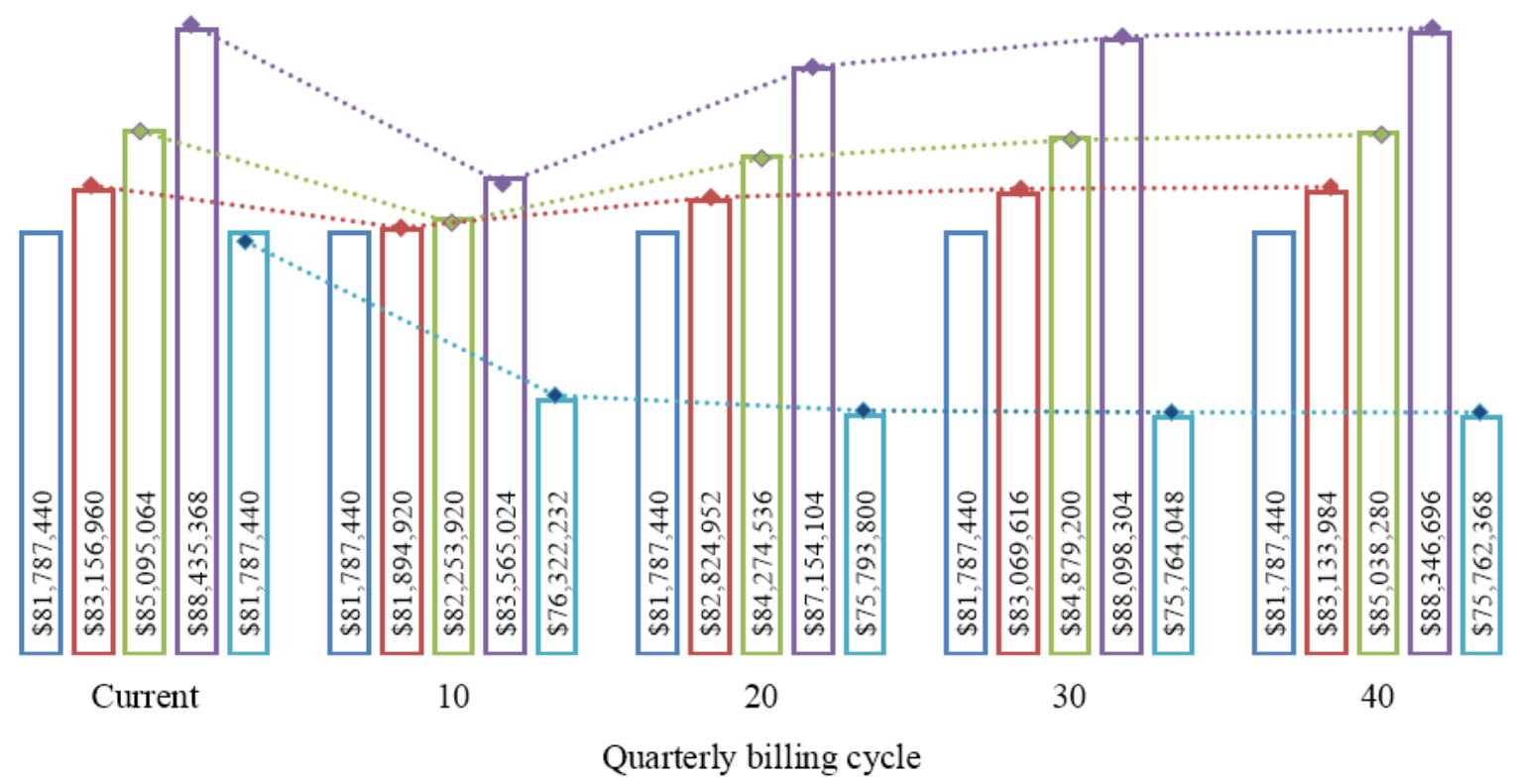

Figure 6. Total revenues per quarter (all customer segments) under five scenarios 
As shown Figure 6, if a restriction strategy was implemented ( $\operatorname{Sen} 5$ ), the water utility's quarterly revenue would be reduced by about $\$ 6$ million ( $\$ 24$ million annually) compared to Scn1, and by about $\$ 13$ million (\$52 million annually) compared to $\mathrm{Scn} 4$. The revenue loss over a simulation period (10 years) would be large enough to cover the large portion of a new supply infrastructure costs (e.g.: the capital cost of the Gold Coast desalination plant with 46 GL per year capacity completed in 2009 was \$1.2 billion (QWC, 2010))

\subsection{Restrictions verse tiered scarcity adjusted water budget and pricing structure}

Potential impacts of pricing and restriction strategies are shown in Table 6. Both options have their own advantages and disadvantages. As shown in Table 6, both options achieve the objective to reduce water consumption during water scarcity periods. The tiered scarcity adjusted water budget and pricing approach better targets high consumers, while restrictions are imposed on all groups. For example, a very water efficient household may be restricted from watering a small garden even though that end use consumption would not cause the household's water usage to go beyond the baseline water budget block. Adversely, restrictions do not prevent or significantly penalise a high consumption household from having very long showers. While most people probably perceive restrictions to be more equitable than scarcity pricing, this paper demonstrates that restrictions are less preferable to scarcity pricing in terms of the long-run marginal cost to achieve water security for a region. Restrictions also significantly reduce revenue for water authorities in periods of water scarcity, i.e. when they typically also embark on capital works programs to secure new/upgraded bulk water supply infrastructure (e.g. new desalination plant or dam level raising). Mandatory restrictions strategies are widely used to conserve water during droughts, however, these strategies are not as successful in signalling water scarcity as pricing strategies. With restrictions, the significance of water saving is not clearly expressed to the customers as the water price remains unchanged. On the other hand, scarcity-driven pricing is flexible and can be removed promptly as soon as a drought ends. Also, implementing restrictions is expensive and includes significant marketing and enforcement costs. Data presented in Figure 5, Figure 6 and Table 5 demonstrates that the pricing strategies provide an incentive to consumers, which rewards those who use less water during scarcity periods, but which also allows people to use water as long as they are willing to pay a premium for it (Duke and Ehemann, 2002).

The tiered scarcity adjusted water budget and pricing concept can be implemented by introducing a two-part tariff in which customers would pay varying rates depending on the block thresholds (i.e. water budget available in each pricing tier) and increasing price for the second block that is adjusted based on a certain water scarcity level (i.e. available or projected water supply at period of time). Readers should note that the water budgets and pricing can adjust both upwards and downwards (i.e. align with scarcity 
level of region). As discussed above, as water becomes scarcer, the water budget for the base price is reduced and the price of the second block increases. However, after a drought has finished and dams replenish to high levels, the adjustments reverse to restore the higher first block water budget and lower the price of second block. Obviously, budgets and pricing can also be reviewed; even with full water supplies, customer water budgets could be reduced slightly over time to reflect appliance and behaviour efficiency trends (e.g. modern clothes washers use less water).

Table 6. Comparing restrictions with tiered scarcity adjusted water budget and pricing structure

\begin{tabular}{lll}
\hline Objective & Pricing & Restrictions \\
\hline Reduction in water consumption during periods of scarcity & yes & yes \\
Target specific groups of customers based on their water consumption & yes & no \\
Maintain equity & yes & no \\
Generating revenue to fund required water security infrastructure & yes & no \\
Implementation flexibility & high & low \\
Implementation cost & low & high \\
Cost recovery & high & low \\
\hline
\end{tabular}

During drought periods, the standard practice in Australia and in many other countries has been a varying level of restrictions, with increasingly severe bans on watering gardens, washing cars, and even using drip irrigation systems. Studies have estimated the cost per person of the restrictions is in excess of $\$ 100$ per household for each dry summer (Grafton and Ward, 2008). This means that in a city with a population of 200,000 homes, the cost of restrictions would be approximately $\$ 20$ million. Given that water supply is often by government-owned monopolies that have a fairly fixed cost base to function, restrictions often lead to lower water usage and lower revenues for the water authority, which in-turn, leads to higher prices in order to maintain the same revenue for the water authority. Therefore, the nature of the industry means that customers that adhered to restrictions and social marketing to reduce their water consumption in a water scarcity period are often rewarded with price increases well above inflation for many years after that dire period has ended.

However, there are also some benefits of using water restrictions. For example, the customer survey results of this study indicated that there is a broad acceptance of water restrictions. This is consistent with the findings of an investigation in 2003, reporting that around 63 percent of people were willing to have water restrictions once every year while only 9 per cent were never willing to accept water restrictions (O'Dea and Cooper, 2008). These survey findings suggest that introducing contemporary scarcity pricing approaches in lieu of water restrictions may not be widely accepted at first and further emphasises the importance of good stakeholder engagement and public consultation before any such arrangement can be successfully introduced to a city. 
In this research, a system dynamics model that utilised both historical data and stakeholder input, was developed to evaluate a novel tiered scarcity adjusted water budget and pricing structure. Results demonstrated that cleverly designed scarcity-driven pricing strategies would be more effective and equitable than water restrictions during periods of drought as restriction strategies disregard the heterogeneous characteristics of customer groups. Water utilities able to implement demand management pricing strategies would also be able to recover the full cost of water supply in the present. Additionally, they will reduce water demand and reward efficient water-use behaviour, thereby contributing to the long-term sustainability of the water resources in the region. Using a SDM approach, the proposed tiered scarcity adjusted water budget and pricing structure was deemed to be superior to traditional water restrictions and static pricing regimes. Fully integrated urban water modelling covering the supply-demand-financial nexus over long-term scenarios allowed the authors to carefully unpack the advantages and disadvantages of different water demand management strategies. The modelling has demonstrated the pitfalls of traditional strategies to manage demand during periods of water scarcity. Static pricing arrangements and restrictions unleash a number of unintended outcomes and often lead to a higher long-run marginal cost of water supply for consumers. As with almost all markets, they operate at their highest efficiency when pricing is linked with availability or scarcity. However, while the presented concept has many merits, it will only be successful if it can be designed and implemented appropriately and equitably, and before that can occur, further research is required. Moreover, while consumers are used to scarcity pricing when they undertake their weekly grocery shop for fruit and vegetables, the concept of scarcity pricing for water is relatively new for most consumers. Social marketing efforts and some other measures would undoubtedly improve consumers' level of understanding and acceptance of this alternative tariff arrangement.

Future research is required to explore various forms of tiered scarcity adjusted water budget and pricing structures. Baseline water budgets for various customer groups must be determined for various levels of water scarcity, to ensure that each group gets an equitable share of water for different conditions. Moreover, appropriate pricing for the second tier (or more) pricing levels (i.e. B2, B3, etc.) need to be determined for various water scarcity levels; this requires significant economic modelling efforts.

The context of the paper's water security assessment is not unique to Australia. Therefore, owing to the use of a SDM approach, the model detailed in this study can provide a framework for assessing a range of integrated urban water planning problems and/or new concepts. 
The authors would like to thank the customer survey respondents, project reference group, project management group, and other stakeholder committees, from the case study city. This research would not have been possible without their valuable input.

\section{References}

Aguirre-Rodriguez, A., 2013. The Effect of Consumer Persuasion Knowledge on Scarcity Appeal Persuasiveness. J Advertising 42, 371-379.

Anand, S., Vrat, P., Dahiya, R.P., 2006. Application of a system dynamics approach for assessment and mitigation of $\mathrm{CO} 2$ emissions from the cement industry. Journal of Environmental Management 79, 383-398.

Arbues, F., Barberan, R., Villanua, I., 2004. Price impact on urban residential water demand: A dynamic panel data approach. Water Resources Research 40.

Barlas, Y., Carpenter, S., 1990. Philosophical roots of model validation: two paradigms. Syst Dynam Rev 6, 148-166.

Beal, C., Stewart, R.A., 2011. South East Queensland Residential End Use Study: Final Report, Urban Water Security Research Alliance Technical Report No. 47, Gold Coast, Australia.

Beal, C.D., Bertone, E., Stewart, R.A., 2012. Evaluating the energy and carbon reductions resulting from resource-efficient household stock. Energy and Buildings 55, 422-432.

Beal, C.D., Gurung, T.R., Stewart, R.A., 2016. Demand-side management for supply-side efficiency: Modeling tailored strategies for reducing peak residential water demand. Sustainable Production and Consumption 6, 1-11.

Beal, C.D., Stewart, R.A., 2014. Identifying Residential Water End Uses Underpinning Peak Day and Peak Hour Demand. Journal of Water Resources Planning and Management 140.

Bennett, N.D., Croke, B.F.W., Guariso, G., Guillaume, J.H.A., Hamilton, S.H., Jakeman, A.J., MarsiliLibelli, S., Newham, L.T.H., Norton, J.P., Perrin, C., Pierce, S.A., Robson, B., Seppelt, R., Voinov, A.A., Fath, B.D., Andreassian, V., 2013. Characterising performance of environmental models. Environ Modell Softw 40, 1-20.

Britton, T.C., Stewart, R.A., O'Halloran, K.R., 2013. Smart metering: enabler for rapid and effective post meter leakage identification and water loss management. J Clean Prod 54, 166-176.

Chong, J., Herriman, J., White, S., Campbell, D., 2009. Review of Water Restrictions-Volume 1 Review and Analysis. Final Report for National Water Commission. Institute for Sustainable FuturesUTS and ACIL Tasman. Available opus.lib.uts.edu.au/bitstream/10453/20462/1/Chongetal2009waterrestrictions.pdf, p. 156.

Cole, G., O'Halloran, K., Stewart, R.A., 2012. Time of use tariffs: implications for water efficiency. Water Science and Technology: Water Supply 12, 90-100.

Crooks, A., Castle, C., Batty, M., 2008. Key challenges in agent-based modelling for geo-spatial simulation. Computers, Environment and Urban Systems 32, 417-430.

Denver Water, 2013. Drought Pricing Schedule. Denver Water,.

Duke, J., Ehemann, R.W., 2002. The conservation of residential water: Scarcity pricing of water in Northern New Castle County. University of Delaware, Department of Food and Resource Economics.

Fielding, K.S., Spinks, A., Russell, S., McCrea, R., Stewart, R., Gardner, J., 2013. An experimental test of voluntary strategies to promote urban water demand management. Journal of Environmental Management 114, 343-351.

Forrester, J.W., 1961. Industrial dynamics, (Students' edition) ed. MIT Press, Cambridge, Mass.

Forrester, J.W., 1968. Industrial Dynamics - Response to Ansoff and Slevin. Management Science 14, 601-618.

Forrester, J.W., 1994. System Dynamics, Systems Thinking, and Soft OR. Syst Dynam Rev 10, $245-$ 256. 
Forrester, J.W., Senge, P.M., 1980. Tests for building confidence in system dynamics models, in: Legasto, A.A., Forrester, J.W., Lyneis, J.M. (Eds.), System Dynamics: TIMS Studies in the Management Science. North-Holland Publishing, New York, pp. 209-228.

Frontier Economics, 2008. Approaches to urban water pricing, Waterlines occasional paper no 7. National Water Commission, Canberra, A.C.T.

Frontier Economics, 2011. Efficient water resource pricing in Australia: an assessment of administered scarcity pricing in urban areas, Waterlines report. National Water Commission, Canberra ACT.

Girard, M., Stewart, R.A., 2007. Implementation of pressure and leakage management strategies on the Gold Coast, Australia: Case study. Journal of Water Resources Planning and Management 133, 210 217.

Grafton, R.Q., Ward, M.B., 2008. Prices versus rationing: Marshallian surplus and mandatory water restrictions. Econ Rec 84, S57-S65.

Guo, H.C., Liu, L., Huang, G.H., Fuller, G.A., Zou, R., Yin, Y.Y., 2001. A system dynamics approach for regional environmental planning and management: A study for the Lake Erhai Basin. Journal of Environmental Management 61, 93-111.

Gurung, T.R., Sharma, A., 2014. Communal rainwater tank systems design and economies of scale. J Clean Prod 67, 26-36.

Hoffmann, M., Worthington, A., Higgs, H., 2006. Urban water demand with fixed volumetric charging in a large municipality: the case of Brisbane, Australia. Aust J Agr Resour Ec 50, 347-359.

Huggett, R.J., 1993. Modelling the human impact on nature : systems analysis of environmental problems. Oxford University Press, Oxford ; New York.

Hughes, N., Hafi, A., Goesch, T., 2009. Urban water management: optimal price and investment policy under climate variability. Aust J Agr Resour Ec 53, 175-192.

Kelly, R.A., Jakeman, A.J., Barreteau, O., Borsuk, M.E., ElSawah, S., Hamilton, S.H., Henriksen, H.J., Kuikka, S., Maier, H.R., Rizzoli, A.E., Delden, H., Voinov, A.A., 2013. Selecting among five common modelling approaches for integrated environmental assessment and management. Environ Modell Softw 47, 159-181.

Kirkwood, C.W., 1998. System Dynamics Methods: A Quick Introduction. College of Business Arizona State University. Available: www.public.asu.edu/ kirkwood/sysdyn/SDIntro/SDIntro.htm.

Langsdale, S., Beall, A., Carmichael, J., Cohen, S., Forster, C., Neale, T., 2009. Exploring the Implications of Climate Change on Water Resources through Participatory Modeling: Case Study of the Okanagan Basin, British Columbia. Journal of Water Resources Planning and Management 135(5), 373-381.

Lee, J., Tanverakul, S.A., 2015. Price elasticity of residential water demand in California. J Water Supply Res T 64, 211-218.

Lopez-Nicolas, A., Pulido-Velazquez, M., Rougé, C., Harou, J.J., Escriva-Bou, A., 2018. Design and assessment of an efficient and equitable dynamic urban water tariff. Application to the city of Valencia, Spain. Environ Modell Softw 101, 137-145.

Loucks, D.P., van Beek, E., 2005. Water resources systems planning and management : an introduction to methods, models and applications. Unesco, Paris.

Nguyen, K.A., Stewart, R.A., Zhang, H., 2013. An intelligent pattern recognition model to automate the categorisation of residential water end-use events. Environ Modell Softw 47, 108-127.

O'Dea, G., Cooper, J., 2008. Water scarcity: Does it exist and can price help solve the problem?, Water - Working paper. Independent Pricing and Regulatory Tribunal of New South Wales, Sydney NSW, AU.

OECD, 2010. Pricing Water Resources and Water and Sanitation Services. OECD Publishing. Available: http://dx.doi.org/10.1787/9789264083608-en.

Olmstead, S.M., Hanemann, W.M., Stavins, R.N., 2007. Water demand under alternative price structures. J Environ Econ Manag 54, 181-198.

Oreskes, N., 2004. Beyond the ivory tower - The scientific consensus on climate change. Science 306, 1686-1686.

Pittock, J., Connell, D., 2010. Australia Demonstrates the Planet's Future: Water and Climate in the Murray-Darling Basin. International Journal of Water Resources Development 26, 561-578. 
Porter, M.G., Downie, D., Scarborough, H., Sahin, O., Stewart, R.A., 2014. Drought and Desalination: Melbourne water supply and development choices in the twenty-first century. Desalination and Water Treatment 55, 2278-2295.

Potomac Economics, 2017. 2016 State of the market meport for the elecricity markets. Independent Market Monitor for ERCOT. Available: https://www.potomaceconomics.com/wpcontent/uploads/2017/06/2016-ERCOT-State-of-the-Market-Report.pdf.

QCA, 2000. Statement of Regulatory Pricing Principles for the Water Sector, in: Authority, Q.C. (Ed.), Brisbane QLD, Australia. Available: www.qca.org.au/getattachment/fba12b74-f307-45e9-91f46dc9cf50509c/Statement-of-Regulatory-Pricing-Principles-for-the.aspx.

Qi, C., Chang, N.B., 2011. System dynamics modeling for municipal water demand estimation in an urban region under uncertain economic impacts. Journal of Environmental Management 92, 1628-1641.

QWC, 2010. South East Queensland water strategy. Queensland Water Commission, City East, Qld.

QWC, 2012. South East Queensland Water Strategy - Annual Report 2012. Queensland Water Commission, City East, Qld.

Sahin, O., Bertone, E., Beal, C.D., 2017. A systems approach for assessing water conservation potential through demand-based water tariffs. J Clean Prod 148, 773-784.

Sahin, O., Siems, R.S., Stewart, R.A., Porter, M.G., 2016. Paradigm shift to enhanced water supply planning through augmented grids, scarcity pricing and adaptive factory water: A system dynamics approach. Environ Modell Softw 75, 348-361.

Sahin, O., Stewart, R.A., Porter, M.G., 2015. Water security through scarcity pricing and reverse osmosis: a system dynamics approach. J Clean Prod 88, 160-171.

Saysel, A.K., Barlas, Y., Yenigun, O., 2002. Environmental sustainability in an agricultural development project: a system dynamics approach. Journal of Environmental Management 64, 247 260.

Scarborough, H., Sahin, O., Porter, M., Stewart, R., 2015. Long-term water supply planning in an Australian coastal city: Dams or desalination? Desalination 358, 61-68.

SEQ Water, 2015. South East Queensland's Water Security Program 2015-2045, Water for life South East Queensland's Water Security Program 2015-2045, 1 ed. Queensland Bulk Water Supply Authority, Ipswich QLD, Australia, p. 196.

Sojda, R.S., 2007. Empirical evaluation of decision support systems: Needs, definitions, potential methods, and an example pertaining to waterfowl management. Environ Modell Softw 22, 269-277.

Sterman, J.D., 1984. Appropriate Summary Statistics for Evaluating Historical Fit of System Dynamics Models. Dynamica 10.

Stewart, R.A., Willis, R.M., Panuwatwanich, K., Sahin, O., 2013. Showering behavioural response to alarming visual display monitors: longitudinal mixed method study. Behaviour \& Information Technology 32, 695-711.

Van den Belt, M., Dietz, T., van den Belt, M., ebrary Inc., 2004. Mediated modeling : a system dynamics approach to environmental consensus building. Island press, Washington, DC.

Vennix, J.A.M., Akkermans, H.A., Rouwette, E.A.J.A., 1996. Group model-building to facilitate organizational change: An exploratory study. Syst Dynam Rev 12, 39-58.

Ventana Systems, 2018. Vensim DSS, 7.2 ed. Ventana Systems, Inc., Harvard, MA.

Vieira, A.S., Stewart, R.A., Beal, C.D., 2015. Air source heat pump water heaters in residential buildings in Australia: Identification of key performance parameters. Energ Buildings 91, 148-162.

Walton, A., Hume, M., 2011. Creating positive habits in water conservation: the case of the Queensland Water Commission and the Target 140 campaign. International Journal of Nonprofit and Voluntary Sector Marketing 16, 215-224.

Williams, A., Lansey, K., Washburne, J., 2009. A dynamic simulation based water resources education tool. Journal of Environmental Management 90, 471-482.

Willis, R.M., Stewart, R.A., Giurco, D.P., Talebpour, M.R., Mousavinejad, A., 2013. End use water consumption in households: impact of socio-demographic factors and efficient devices. Journal of Cleaner Production 60, 107-115. 